\title{
EFEITO DO TEOR DE FERRO RESIDUAL NO TAMANHO DE GRÃO E NAS PROPRIEDADES MECÂNICAS DO LATÃO 70/30*
}

\section{Resumo}

Neste trabalho é estudado o efeito do ferro no tamanho de grão e nas propriedades mecânicas do latão UNS C26000, também comercialmente conhecido como latão 70/30. Foram avaliados dois teores residuais: $0,0069 \%$ e $0,0592 \%$. As amostras foram inicialmente laminadas até a espessura de $2,30 \mathrm{~mm}$, submetidas a tratamento térmico de recozimento objetivando tamanho de grão de $0,030 \mathrm{~mm}$. Posteriormente as amostras foram laminadas para outras três espessuras e submetidas a um novo recozimento. As amostras recozidas passaram por análise de tamanho de grão e foram submetidas a ensaios de tração, sendo obtidos resultados de limite de resistência à tração. Os comportamentos apresentados pelos materiais foram distintos entre si, sendo que o material com maior teor de ferro apresentou aumento das propriedades mecânicas em função do aumento da redução de espessura e o material com menor teor ferro apresentou redução do limite de resistência à tração. Quanto ao tamanho de grão, o material com menor teor de ferro apresentou pequena variação de tamanho de grão após o recozimento, enquanto o material com maior teor de ferro apresentou redução do tamanho de grão em função do aumento da redução de espessura, demonstrando inibição do crescimento de grão e estrutura heterogênea.

Palavras-chave: Latão 70/30; Latão C26000; Ferro; Tamanho de grão.

\section{THE RESIDUAL IRON CONTENT EFFECT ON THE GRAIN SIZE AND MECHANICAL PROPERTIES OF 70/30 BRASS}

\begin{abstract}
This work evaluates the effect of residual iron content on the grain size and mechanical properties of brass alloy UNS C26000, also known as 70/30 brass or cartridge brass. Two residual iron contents were evaluated, $0,0069 \%$ e $0,0592 \%$. The materials were rolled to $2.30 \mathrm{~mm}$ and annealed to a grain size of $0.030 \mathrm{~mm}$. Then the samples were rolled to three different thickness and annealed. The grain size and mechanical properties of the annealed samples were evaluated. The materials had different behaviors. The alloy containing higher iron content had a positive influence of the previous strain on the mechanical properties of the annealed material, while the alloy containing the smaller iron content had an opposite behavior. The increase of previous strain had also a great influence on the gran size of the higher iron content alloy, which was not observed for the other alloy. The results show that the higher residual iron content causes grain growth inhibition and a heterogeneous microstructure.
\end{abstract}

Keywords: Brass 70/30; Brass C26000; iron; Grain size.

Mestre, Engenheiro na Paranapanema SA. Santo André-SP, Brasil.

Engenheiro na Paranapanema SA. Santo André-SP, Brasil.

Gerente de Processos e Produção na Paranapanema SA. Santo André-SP, Brasil. 


\section{INTRODUÇÃO}

A utilização de matéria prima reciclada vem sendo amplamente praticada pela indústria metalúrgica por diversos fatores, que vão de questões ambientais a financeiras. Em geral, essas matérias primas contêm impurezas que podem ser desconhecidas até o momento da fundição dos produtos. Com isso, podem ocorrer variações nas propriedades mecânicas do material a ser produzido, como por exemplo, devido à variação do tamanho de grão após o tratamento térmico de recozimento.

Para o caso particular em estudo, alguns trabalhos podem ser encontrados na literatura sobre o efeito do ferro em ligas cobre-zinco. Khafri e Jouibari [1], mostram que adições de ferro na faixa de 0,20\% e 0,35\% ao latão 70/30 causam uma redução do tamanho de grão final após recozimento. Os limites de escoamento e de tração sofrem um aumento, enquanto a ductilidade é reduzida. $\mathrm{Na}$ faixa de concentração do trabalho, encontram-se finos precipitados intermetálicos ricos em ferro dispersos na matriz. Shafiei e colaboradores [2], investigaram a influência de adições de ferro $(0,30 \%)$ sobre a cinética de recristalização do latão $70 / 30$. Os autores observaram que nessas amostras a recristalização ocorreu de forma muito mais lenta. Embora não se tenha pesquisado a formação de intermetálicos, ela deve ocorrer para as amostras em questão, uma vez que o trabalho de Khafri e Jouibari [1] mostrou sua formação mesmo para teores menores $(0,20 \%)$.

Os estudos citados foram realizados em condições de adição intencional de ferro em teores muito acima dos residuais encontrados industrialmente e alvos deste trabalho. Na faixa de teores residuais de ferro, os trabalhos de Moreira [3] e Moreira e Tschiptschin [4] indicam que a recristalização não é afetada pelo aumento do teor de ferro, mas que, por outro lado, o crescimento de grão é fortemente dependente da concentração deste elemento. Este efeito é tanto mais pronunciado quanto menor a temperatura de recozimento.

$\mathrm{Na}$ literatura pesquisada, no entanto, não se encontrou nenhum trabalho de investigação sobre a interação do grau de deformação e o teor residual de ferro sobre o recozimento de latões. Assim, o objetivo deste trabalho é avaliar o efeito do teor de ferro residual, associado ao grau de deformação do latão 70/30 imposto por laminação a frio, sobre tamanho de grão e as propriedades mecânicas desta liga após tratamento térmico de recozimento.

\section{MATERIAIS E MÉTODOS}

Neste trabalho, foram analisadas amostras de tiras laminadas da liga UNS C26000, também conhecido como latão 70/30, com variação do teor de ferro residual em dois valores, conforme apresentado na Tabela 1. Por praticidade, as amostras serão nomeadas neste trabalho como $\mathrm{Fe}-(0,0069 \% \mathrm{Fe})$ e $\mathrm{Fe}+(0,0592 \% \mathrm{Fe})$.

Inicialmente, foram fundidas placas com espessura de $160 \mathrm{~mm}$ e laminadas a quente para a espessura de $14 \mathrm{~mm}$. Em seguida, os materiais foram laminados a frio em um laminador industrial do tipo Quadruo até espessura de 2,30 +/- 0,06 mm. As amostras foram então retiradas no sentido de laminação e na região central das chapas. Foi realizado um tratamento térmico em forno elétrico do tipo Mufla, seguindo os parâmetros da Tabela 2, com objetivo de se atingir o mesmo tamanho de grão para os dois materiais. 
Tabela 1. Composição química dos materiais, em porcentagem mássica.

\begin{tabular}{cccccc} 
Amostra & $\mathrm{Cu}[\%]$ & $\mathrm{Zn} \mathrm{[ \% ]}$ & $\mathrm{Fe} \mathrm{[ \% ]}$ & Sn [\%] & Pb [\%] \\
\hline $\mathrm{Fe}-$ & 68,9600 & 30,9973 & 0,0069 & 0,0224 & 0,0134 \\
\hline $\mathrm{Fe}^{+}$ & 68,9900 & 30,9342 & 0,0592 & 0,0213 & 0,0133 \\
\hline
\end{tabular}

Tabela 2. Parâmetros do tratamento térmico de recozimento

\begin{tabular}{ccc}
\hline Amostra & $\begin{array}{c}\text { Temperatura } \\
{\left[{ }^{\circ} \mathrm{C}\right]}\end{array}$ & $\begin{array}{c}\text { Tempo } \\
{[\mathrm{min}]}\end{array}$ \\
\hline $\mathrm{Fe}-$ & 490 & 180 \\
\hline $\mathrm{Fe}+$ & 540 & 180
\end{tabular}

Após o primeiro recozimento, as amostras foram laminadas em um laminador de Ourives para três novas espessuras, sendo os valores mostrados na Tabela 3.

Tabela 3. Espessuras de laminação do material recozido.

\begin{tabular}{ccc}
$\begin{array}{c}\text { Espessura } \\
\text { inicial [mm] }\end{array}$ & $\begin{array}{c}\text { Espessura } \\
\text { Final [mm] }\end{array}$ & Redução [\%] \\
\hline $2,30+/-0,06$ & $1,22+/-0,03$ & $47 \%$ \\
\hline $2,30+/-0,06$ & $0,80+/-0,02$ & $65 \%$ \\
\hline $2,30+/-0,06$ & $0,39+/-0,02$ & $83 \%$
\end{tabular}

O recozimento final foi realizado com os mesmos parâmetros para todas as amostras, também em forno mufla: temperatura de $490^{\circ} \mathrm{C}$ por um período de 180 minutos.

Para análise metalográfica, as amostras foram lixadas em lixas de grana \#360 e \#800, e posteriormente polidas utilizando pasta de diamante de 6 e $1 \mu \mathrm{m}$. A microestrutura foi então revelada com reagente trióxido de cromo por imersão durante 5 segundos. $O$ tamanho de grão dos materiais foi analisado de acordo com o método comparativo proposto pela norma ASTM E112 [5], utilizando microscópio óptico marca Olympus, modelo BX60M com aumento de 75 vezes.

Os corpos de prova de ensaios de tração froam do tipo "subsize", de acordo a norma ASTM E8 [6]. Os corpos de prova foram fresados e testados em um equipamento vertical marca Instron, modelo 5980, com velocidade de $15 \mathrm{~mm} / \mathrm{min}$. Como resultados foram extraídos os valores de resistência à tração (LRT) e alongamento.

\section{RESULTADOS E DISCUSSÃO}

Os resultados de limite de resistência à tração mínimo, máximo e sua média são apresentados na Figura 1. É possível notar comportamentos distintos entre os dois materiais após recozimento, em função do grau de redução. O material Fe- apresentou variação negativa de $39 \mathrm{MPa}$ entre o estado recozido e a condição de $82 \%$ de redução e recozimento. Por outro lado, para o material $\mathrm{Fe}+$, esta mesma 
variação foi positiva de $27 \mathrm{MPa}$. O ferro em teor mais elevado $(0,0592 \%)$ combinado com o aumento da deformação, contribui para o aumento do limite de resistência à tração após o recozimento.

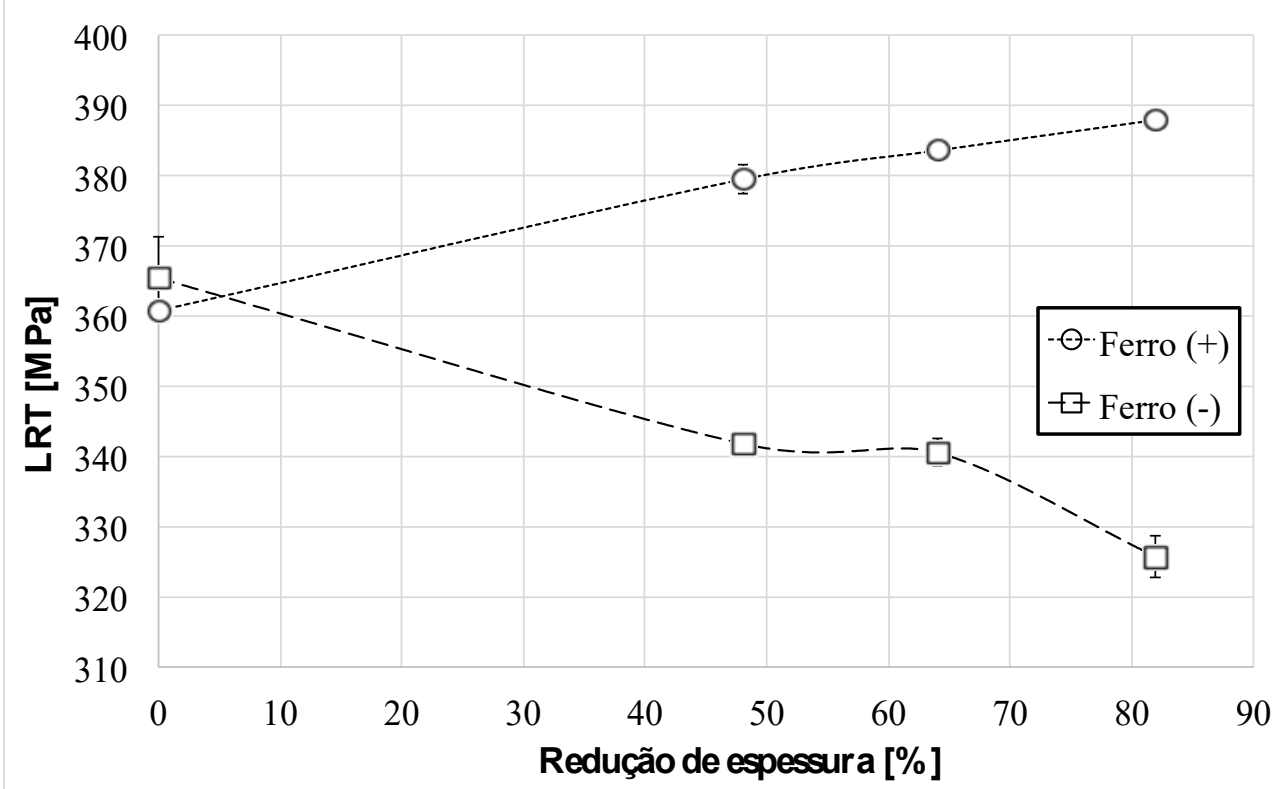

Figura 1. Limite de resistência à tração em função do percentual de redução para os materiais $\mathrm{Fe}-\mathrm{e}$ $\mathrm{Fe}+$.

Os resultados de tamanho de grão após recozimento são apresentados na Figura 2 em função da redução de espessura para os dois materiais. Nota-se que, para o material Fe-, houve pequena diminuição do tamanho de grão médio para as reduções de $47 \%$ e $65 \%$, e pequeno aumento para $83 \%$ de deformação. Por outro lado, para o material $\mathrm{Fe}+$ houve redução bastante intensa e monotônica do tamanho de grão médio em função da redução de espessura, variando de 0,030 a $0,005 \mathrm{~mm}$. Para todas as condições de recozimento, o material $\mathrm{Fe}+$ apresentou tamanho de grão consideravelmente menor.

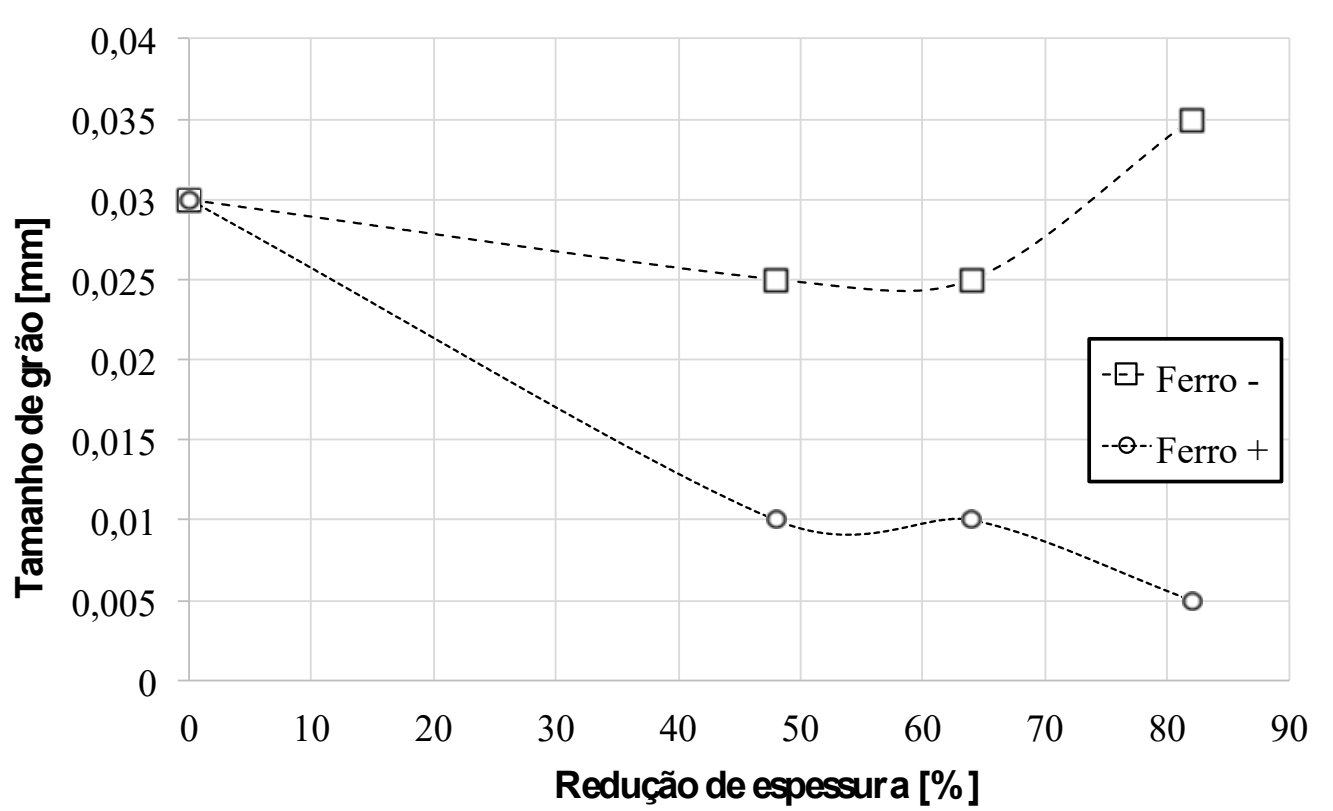

Figura 2. Tamanho de grão em função do percentual de redução para os materiais $\mathrm{Fe}-\mathrm{e} \mathrm{Fe}+$. 
É importante destacar que, no material com ferro em teores reduzidos $(0,0069 \%)$, não houve grande influência de tamanho de grão com o aumento de deformação a que o material foi submetido. O limite de resistência à tração, de forma geral, acompanhou a variação de tamanho de grão. Porém, o material com ferro em teor maior, combinado com o aumento da deformação, causou inibição do crescimento de grão durante o recozimento. Com isso, o limite de resistência à tração das amostras aumentou com o grau de redução, como previsto pela relação de HallPetch entre resistência à tração e tamanho de grão. Essa relação é ilustrada na Figura 3.

Uma importante característica das amostras com teor de ferro mais elevado $(\mathrm{Fe}+)$ é uma considerável heterogeneidade microestrutural. Essa característica resulta em desempenho ruim durante processos de conformação, como a estampagem.

É importante também observar que para ambos os materiais, não foi notada variações significativas no tamanho de grão o nas propriedades mecânicas das amostras com $47 \%$ e $65 \%$ de redução por laminação.

Como discutido no trabalho de Moreira [3], o efeito da inibição de crescimento de grão pode ser resultado da formação de partículas dispersas de ferro, formando clusters, ou mesmo pelo efeito de átomos de ferro como soluto segregado em contornos de grão. O efeito do grau de deformação, neste caso, pode ter origem na dispersão dessas partículas ou na redistribuição de solutos.

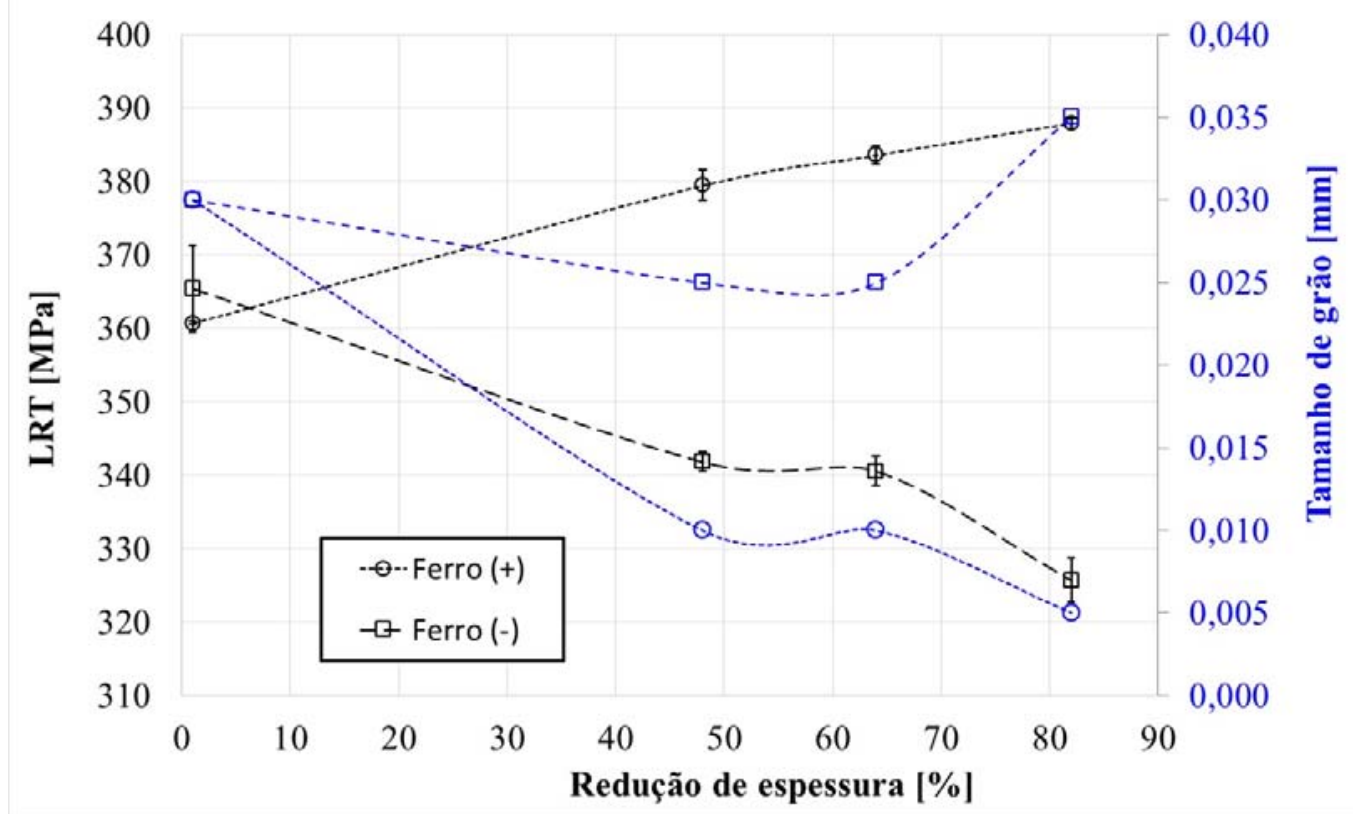

Figura 3. LRT e tamanho de grão em função da redução por passe.

\section{CONCLUSÃO}

Nas condições experimentais deste trabalho, o elemento químico ferro presente como impureza no latão UNS C26000 exerceu influência significativa no recozimento do material. O aumento do grau de redução de espessura antes do recozimento resultou em aumento do limite de resistência à tração e diminuição do tamanho de grão médio, para a amostra $\mathrm{Fe}+\mathrm{Na}$ comparação com as amostras com $\mathrm{Fe}$-, observa-se que o teor de ferro elevado causa inibição do crescimento de grão e heterogeneidade microestrutural. Essas características em conjunto provavelmente pioram o desempenho do material em processos de conformação, como a estampagem. 


\section{Agradecimentos}

Os autores agradecem a Paranapanema SA., pelo incentivo a pesquisa e por permitir esse e outros trabalhos.

\section{REFERÊNCIAS}

1 Agahie-Kahfri M, Mohebati-Jouibari A. Thermomechanical treatment of 70/30 brass containing iron impurity. Journal of Materials Science. 2006;41:7585-7589.

2 Shafiei A, Roshanghias A, Abbaszadeh H, Akbari GH. An investigation into the effect of alloying elements on the recrystallization behavior of $70 / 30$ brass. Journal of Materials Engineering and Performance. 2010;19(4):553-557.

3 Moreira VC. Efeito do teor residual de Fe no recozimento do latão 70/30. Dissertação (Mestrado) - Escola Politécnica da Universidade de São Paulo. Departamento de Engenharia Metalúrgica e de Materiais. 2015; 127 p.

4 Moreira VC, Tschiptschin AP. A dilatometric study of the influence of residual iron content on the annealing behavior of cartridge brass. 2016;19(2):483-489.

5 ASTM E 112: Standard Test Method for Determining Average Grain Size. United States. 2013.

6 ASTM E 8: Standard Test Method for Tension Testing of Metallic Materials. United States. 2015. 